\title{
Oncolytic virotherapy for human malignant mesothelioma: recent advances
}

This article was published in the following Dove Press journal:

Oncolytic Virotherapy

10 September 2015

Number of times this article has been viewed

\author{
Nicolas Boisgerault ${ }^{1-3}$ \\ Carole Achard ${ }^{1-3}$ \\ Tiphaine Delaunay ${ }^{1-3}$ \\ Laurent Cellerin ${ }^{4}$ \\ Frédéric Tangy ${ }^{5}$ \\ Marc Grégoire ${ }^{1-3}$ \\ Jean-François Fonteneau ${ }^{1-3}$ \\ 'INSERM, UMR892, '2CNRS, UMR6299, \\ Health Research Institute of the \\ University of Nantes, ${ }^{3}$ University \\ of Nantes, ${ }^{4}$ Nantes CHU Hospital, \\ Department of Thoracic and Digestive \\ Oncology, ${ }^{5}$ Viral Genomics and \\ Vaccination Unit, Institut Pasteur, \\ Paris, CNRS UMR-3569, France
}

\begin{abstract}
Cancer virotherapy is an attractive alternative to conventional treatments because it offers a wide range of antitumor effects due to 1) the diversity of the oncolytic viruses that are now available and 2) their multifaceted activities against both tumor cells and tumor vessels, in addition to their ability to induce antitumor immune responses. In this review, we summarize preclinical and clinical data regarding the targeting of malignant mesothelioma (MM) by oncolytic viruses. We also discuss the potential of other oncolytic viruses that have already shown antitumor effects against several malignancies in advanced clinical trials but are yet to be tested against MM cells. Finally, we review how the activation of the immune system and combinations with other types of anticancer treatments could support the development of oncolytic virotherapy for the treatment of MM.
\end{abstract}

Keywords: oncolytic viruses, cancer virotherapy, malignant mesothelioma, antitumor immune responses, immunotherapy

\section{Introduction}

Oncolytic viruses are either naturally occurring or genetically engineered viruses that are able to target tumor cells preferentially over healthy cells. ${ }^{1}$ Such viruses have been shown to exert antitumor activity against numerous types of human cancers, and several are currently being tested in the final phases of clinical trials. Their ability to not only kill cancer cells specifically but also both impair abnormal vasculature and stimulate different types of immune effectors makes them potent therapeutic agents that are adapted to a variety of clinical situations. One can expect that some of these oncolytic viruses will be routinely used to treat clinically challenging malignancies within a few years.

Questions remain regarding treatment modalities, eg, when deciding the route of administration or the number of injections that would be necessary to achieve significant antitumor responses. One of the major pending issues relates to the ability of the oncolytic vectors to escape from antiviral mechanisms - such as neutralizing antibodies that are present in body fluids or type I interferon pathways - that could dampen their antitumor efficacy. When applicable, the use of intratumor or intracavity injections may be advocated, which are expected to increase the probability of contact between the virus and the tumor cells while limiting neutralization of the viral particles before they reach the tumor site. As an example, patients with advanced ovarian cancers who were immune to measles virus (MV) were shown to be efficiently treated by intraperitoneal injections of an oncolytic strain of $\mathrm{MV}^{2,3}$ Other malignancies that
Correspondence: Nicolas Boisgerault INSERM, UMR892 - CNRS UMR6299, Institut de Recherche Thérapeutique de I'Université de Nantes, 8 quai Moncousu, BP7072 I, 44007 Nantes Cedex I, France Tel +33228080236

Fax +33 228080204

Email nicolas.boisgerault@inserm.fr 
are known to arise in or metastasize to body cavities thus make good candidates for similar approaches.

In this review, we discuss the aspects that make virotherapy a good alternative to conventional treatments for malignant mesothelioma (MM), an aggressive cancer that affects the cells delineating different body cavities and for which an efficient treatment is yet to be designed. We summarize data that have been collated over the past 2 decades in order to support further investments for the development of virotherapeutic strategies for patients with MM.

\section{Malignant mesothelioma}

Asbestos exposure has been known for several decades to cause various respiratory diseases. One of the most illustrative pathologies related to occupational asbestos exposure is malignant pleural mesothelioma (MPM), an incurable cancer affecting pleural mesothelial cells. ${ }^{4,5}$ These cells are normally constitutive of the two membranes - the parietal pleura and the visceral pleura - that surround and protect the lungs. MM can also, rarely, arise from mesothelial cells delineating the pericardium (heart), the peritoneum (abdomen), or the tunica vaginalis testis and tunica serosa uteri (reproductive organs).

MPM is characterized by pleural thickening, the formation of pleural plaques and the accumulation of pleural fluid - known as pleural effusion - between the two layers of the pleura. This malignancy is commonly diagnosed several decades after exposure to asbestos, with symptoms that can be mistaken for those of invasive lung cancer or of pleural metastases from other types of cancers. ${ }^{6}$ It is an extremely aggressive neoplasm, resistant to conventional treatments including surgery, chemotherapy, and radiotherapy. Outcomes for this disease are extremely poor, with a survival rate of approximately $40 \% 1$ year after diagnosis and only $10 \%$ after 5 years. ${ }^{7}$

These clinical hurdles make MM a suitable candidate for innovative therapeutic approaches such as oncolytic virotherapy, with the aim of improving its clinical management. Because the treatment of pleural effusion indeed requires access to the pleural cavity, local injections of oncolytic viruses into the pleural or the peritoneal cavities could be envisioned.

\section{Herpesvirus}

Several DNA viruses from the Herpesviridae family have been investigated for their oncolytic properties. ${ }^{1}$ The most advanced, talimogene laherparepvec ( $\mathrm{T}-\mathrm{Vec}$ ), previously known as OncoVEX ${ }^{\mathrm{GM}-\mathrm{CSF}}$, is an oncolytic herpesvirus (HSV) that showed significant antitumor activity after intratumoral injection in a recent Phase II clinical trial for the treatment of melanoma. ${ }^{8}$ This virus is currently being tested in a Phase III study and is expected to be shortly approved for clinical use by the US Food and Drug Administration.

$\mathrm{T}-\mathrm{Vec}$ has not yet been used in patients with MM, but other strains of HSV have been studied for their ability to target and specifically kill mesothelioma cells. In 1997, it was first shown that replication-restricted HSV-1716 could eliminate human MM cells both in vitro and in immunodeficient mice. ${ }^{9}$ In the following years, Adusumilli et al published several articles in which they showed that different oncolytic HSV vectors were relevant therapeutic agents to target human $\mathrm{MM}$, alone or in combination with other types of anticancer treatments. ${ }^{10-13} \mathrm{HSV}-1716$ is currently being investigated in a Phase I/IIa trial to determine the safety and efficacy of single or multiple intrapleural administrations of the virus in patients with MPM (Table 1).

Other strains of oncolytic HSV, such as G207, NV1020, and NV1066, that code for fluorescent proteins have also been used to treat and image primary tumors and metastases of mesothelioma in vivo. ${ }^{12-14}$ This alternative use of oncolytic viruses identified minimal residual disease and lymph node metastases in animal models. Such an approach could participate in improving the clinical management of MM.

\section{Poxvirus}

JX-594, also known as pexastimogene devacirepvec (Pexa-Vec), is another oncolytic virus expected to be tested in a Phase III clinical trial for patients with hepatocellular carcinoma. In the prior Phase II study, regression of both the injected tumors and tumors distant from the injection site were observed, suggesting the induction of an antitumor immune response..$^{15}$ Interestingly, half the patients were seropositive for vaccinia virus prior to the treatment, but the therapy was efficient in all patients independent of their immune status.

In the corresponding Phase I study that was conducted in patients with different types of solid tumors, a single patient with metastatic MPM was included and showed partial remission for more than 10 weeks after a single intravenous injection of the virus. ${ }^{16}$ Another Phase I trial is underway for patients with malignant pleural effusions of different origins, including those with MPM (Table 1). This group of researchers previously showed that such an oncolytic virus could specifically target human MM cells in vitro and in an orthotopic animal model. ${ }^{17-19}$ Another vaccinia virus was also recently shown to treat $\mathrm{MM}$ efficiently in vivo in association with cytoreductive surgery. ${ }^{20}$ In 2000 , a first study showed that a recombinant vaccinia virus encoding the interleukin-2 
Table I Completed and ongoing clinical trials of virotherapy for malignant mesothelioma treatment

\begin{tabular}{|c|c|c|c|c|c|}
\hline Virus & Phase & Patients & Treatment modalities & Results & Reference \\
\hline \multicolumn{6}{|l|}{ Adenovirus } \\
\hline Ad.HSVtk & 1 & $21 \mathrm{MPM}$ & $\begin{array}{l}\text { No previous therapy } \\
\text { Intrapleural injection } \\
\left.\text { ( } \geq 1.5 \times 10^{13} \text { particles }\right) \\
\text { + systemic ganciclovir }\end{array}$ & $\begin{array}{l}\text { Well tolerated } \\
\text { Antitumor antibodies } \\
2 \text { long-term survivors } \\
\text { (>6.5 years) }\end{array}$ & 55 \\
\hline $\begin{array}{l}\text { Ad.hIFN- } \beta \\
(\text { BG0000I) }\end{array}$ & 1 & $\begin{array}{l}7 \text { MPM } \\
3 \text { metastatic pleural effusions } \\
\text { (ovary, lung, MPM) }\end{array}$ & $\begin{array}{l}\text { No previous therapy } \\
\text { Single intrapleural injection } \\
\left(9 \times 10^{11}-3 \times 10^{12} \text { particles }\right)\end{array}$ & $\begin{array}{l}\text { Antitumor immune } \\
\text { response in } 7 / 10 \text { patients } \\
\text { Clinical response (SD) in } \\
4 / 10 \text { patients }\end{array}$ & 35 \\
\hline $\begin{array}{l}\text { Ad.hIFN- } \beta \\
(\text { BG0000I) }\end{array}$ & 1 & $\begin{array}{l}\text { I } 0 \text { epithelioid MPM } \\
7 \text { metastatic pleural effusions } \\
\text { (ovary, lung, breast) }\end{array}$ & $\begin{array}{l}2 \text { intrapleural injections } \\
(7 \text {-day interval) } \\
\left(3 \times 10^{11}-1 \times 10^{12} \text { particles }\right)\end{array}$ & $\begin{array}{l}\text { Well tolerated } \\
\text { Antibody responses against } \\
\text { tumor antigens } \\
\text { I PR, } 2 \text { SD, } 7 \text { with } \\
\text { survival > } 18 \text { months }\end{array}$ & 36 \\
\hline $\begin{array}{l}\text { Ad.hIFN- } \alpha 2 b \\
(\mathrm{SCH} 721015)\end{array}$ & Pilot & 9 MPM & $\begin{array}{l}2 \text { intrapleural injections } \\
\text { (3-day interval) } \\
\left(3 \times 10^{11}-1 \times 10^{12} \text { particles }\right)\end{array}$ & $\begin{array}{l}\text { Well tolerated } \\
\text { Neutralizing antibodies } \\
\text { I PR and } 2 \text { SD }\end{array}$ & 34 \\
\hline $\begin{array}{l}\text { Ad.hIFN- } \alpha 2 b \\
(\mathrm{SCH} 72|0| 5)\end{array}$ & $\mathrm{I} / \mathrm{II}$ & MPM & $\begin{array}{l}2 \text { intrapleural injections } \\
+4-6 \text { cycles of chemotherapy }\end{array}$ & Ongoing & NCTOIII9664a \\
\hline $\begin{array}{l}\text { Ad.hIFN- } \alpha 2 b \\
(\mathrm{SCH} 72 \mathrm{I} 015)\end{array}$ & 1 & MPM & $\begin{array}{l}2 \text { intrapleural injections } \\
\text { (3-day interval) }\end{array}$ & Ongoing & NCTOI $212367^{a}$ \\
\hline Ad5-D24-GMCSF & Unspecified & 2 MPM & $\begin{array}{l}\text { After chemotherapy } \\
\text { Single intrapleural injection } \\
\left(2.5 \times 10^{11}-3 \times 10^{\prime 1} \text { particles }\right)\end{array}$ & $\begin{array}{l}\text { Well tolerated } \\
\text { Tumor-specific and virus- } \\
\text { specific immunity } \\
\text { I SD and I PD }\end{array}$ & 54 \\
\hline $\begin{array}{l}\text { Ad5/3-D24-GMCSF } \\
\text { (ONCOS-102) }\end{array}$ & 1 & I MPM & $\begin{array}{l}\text { After chemo-/radiotherapy } \\
4 \text { intratumoral injections } \\
\left(3 \times 10^{11} \text { particles) }\right. \\
+ \text { cyclophosphamide (daily) }\end{array}$ & $\begin{array}{l}\text { T CD8 } 8^{+} \text {tumor infiltration } \\
\text { Thl polarization }\end{array}$ & 65 \\
\hline \multicolumn{6}{|l|}{ Poxvirus } \\
\hline VV-IL2 & & 6 MPM & Intratumoral injection & $\begin{array}{l}\text { Well tolerated } \\
\text { No tumor regression }\end{array}$ & 21 \\
\hline $\begin{array}{l}\text { JX-594 } \\
\text { (pexastimogene } \\
\text { devacirepvec) }\end{array}$ & 1 & I metastatic MPM & $\begin{array}{l}\text { After chemotherapy } \\
\text { Single intravenous injection } \\
\left.\text { ( } 1.5 \times 10^{7} \text { particles }\right)\end{array}$ & PR over 10 weeks & 16 \\
\hline GL-ONCI & 1 & $\begin{array}{l}\text { Malignant pleural effusions } \\
\text { (primary, metastases, and } \\
\text { MPM) }\end{array}$ & Intrapleural injection & Ongoing & NCTOI766739a \\
\hline \multicolumn{6}{|l|}{ Reovirus } \\
\hline Reolysin & 1 & I MPM & $\begin{array}{l}\text { Pretreatment with docetaxel } \\
\text { Intravenous injection } \\
\left(I \times 10^{9}-3 \times 10^{10} \mathrm{TCID}_{50}\right) \\
\text { Up to } 8 \text { cycles (every } 21 \text { days) } \\
\text { of } 5 \text { daily injections }\end{array}$ & $\begin{array}{l}\text { Minor response } \\
23 \% \text { size decrease for } \\
I \text { invaded lymph node }\end{array}$ & 48 \\
\hline \multicolumn{6}{|l|}{ Measles virus } \\
\hline MV-NIS & 1 & MPM & $\begin{array}{l}\text { Intrapleural injections } \\
\text { Up to } 6 \text { cycles (every } 28 \text { days) }\end{array}$ & Ongoing & NCTOI503I77a \\
\hline Herpesvirus & & & & & \\
\hline HSV-I7I6 & $\mathrm{l} / \mathrm{lla}$ & MPM & $\begin{array}{l}\text { Single/multiple intrapleural } \\
\text { injections }\end{array}$ & Ongoing & NCTOI721018 \\
\hline
\end{tabular}

Note: aNCT references can be viewed at https://clinicaltrials.gov/

Abbreviations: Ad, adenovirus; GM-CSF, granulocyte-macrophage colony-stimulating factor; IL2, interleukin-2; MPM, malignant pleural mesothelioma; PD, progressive disease; PR, partial remission; SD, stable disease; VV, vaccinia virus; TCID, tissue culture infective dose.

gene could be safely delivered to the pleural cavity to target tumor cells and was then able to attract immune cells to the tumor site. ${ }^{21}$

As with HSVs, oncolytic vaccinia viruses can be used for imaging purposes by using vectors recombinant for radioelement transporters. ${ }^{17,18}$ This facilitates the detection of orthotopic tumors in mice by scintigraphy, positron emission tomography, or single-photon emission computed tomography. This could be of great value when monitoring tumors in patients treated by virotherapy. 


\section{Adenovirus}

Adenoviral vectors have been widely used in viral gene therapy experiments because of the possibilities they offer for genetic engineering. As a consequence, oncolytic adenoviruses come in many varieties that were created to display specific antitumor properties against different types of human tumors. The first oncolytic virus to be approved for clinical use was the adenovirus H101 for the treatment of head and neck cancer in the People's Republic of China in 2006. ${ }^{22}$

Several approaches have been developed to exploit tumor alterations that could favor specific replication of adenoviruses in MM cells compared with the surrounding healthy tissues. These approaches mainly rely on the use of tumor-specific, promoter-regulated adenoviruses using promoters such as those of the survivin, ${ }^{23} C R E B B P / E P 300$ inhibitory protein $1,{ }^{24}$ telomerase, ${ }^{25}$ and midkine ${ }^{26-28}$ genes that can be highly active in MM cells. The use of specific promoters guarantees the safety of oncolytic adenoviruses that are then unable to replicate in nonmalignant cells. A similar strategy was used with an adenovirus dependent on a mesothelin promoter that showed specific antitumor activity in ovarian cancer, but to date, this virus has not been tested against mesothelioma cells. ${ }^{29}$

Other types of viral therapy have been developed against $\mathrm{MM}$, eg, by inserting genes encoding tumor suppressors or immunostimulatory molecules into adenoviral vectors. Some reports show that such vectors can be used to exploit the $\mathrm{p} 53$ status of MM cells. An E1B-55 kDa-defective adenovirus can thus activate $\mathrm{p} 53$ in p53-mutated MM tumors to promote killing of the tumor cell, ${ }^{30}$ while an adenovirus encoding p53 was shown to activate apoptotic pathways in MM cells. ${ }^{31}$ Similar strategies were used to reexpress $p 14$ or $p 16$ tumor suppressor genes. ${ }^{32,33}$ These do not qualify as "oncolytic virotherapy" per se, but such approaches have allowed scientists and clinicians to test the safety and efficacy of intrapleural gene delivery to treat MM in the clinical setting (Table 1). ${ }^{34-36}$ These different studies showed that intrapleural delivery of viral vectors is well tolerated and also provides specific modes of action that can be beneficial for the treatment of MM, especially by activating the antitumor immune response. ${ }^{37}$

\section{RNA viruses}

Several attenuated RNA viruses have been shown to exert oncolytic activity against a wide variety of human tumor types. Among these, vesicular stomatitis virus (VSV), MV, Sendai virus, Newcastle disease virus, reovirus, and even retroviruses have been specifically investigated for their ability to target and kill human MM cells.
VSV encoding the $I F N-\beta$ gene specifically replicates in tumor cells deficient for the type I interferon pathways and shows anti-MM effects. ${ }^{38,39}$ Alterations of type I interferon pathways in human MM cells should also be considered when planning oncolytic virotherapy strategies with other viruses in patients with MM. Indeed, we recently described - in tumor cells derived from 22 patients with MPM - how type I interferon deficiencies could discriminate between patients who would be susceptible to oncolytic MV virotherapy and those who would be resistant to this type of treatment (Achard et al, unpublished data, 2015). Nonetheless, we had previously shown that MV was able to target and kill human mesothelioma cells, ${ }^{40}$ which was then confirmed by another team at the Mayo Clinic. ${ }^{41} \mathrm{~A}$ Phase I clinical trial is thus in progress to investigate intrapleural delivery of MV in patients with MPM (Table 1).

MV was also shown to be an excellent platform to express different reporter transgenes such as the carcinoembryonic antigen ${ }^{3,42}$ or a sodium-iodide symporter ${ }^{43}$ that allow for better monitoring of oncolytic MV targeting and replication in patients, which could be applied to MM. Data from MV are believed to be translatable to canine distemper virus, which could be a valuable vector to test oncolytic virotherapy in dog models of MM. ${ }^{44}$ Sendai virus, another paramyxovirus related to MV, has also been shown to specifically target human MM in a xenograft model. ${ }^{45}$ From the same family, Newcastle disease virus showed similar antitumor activity against numerous human MM cell lines. ${ }^{46}$

Reoviruses, in particular Reolysin, which has been successfully tested in a Phase II trial for patients with metastatic melanoma ${ }^{47}$ are other promising oncolytic agents. So far, only one patient with metastatic MPM has been included in a clinical trial using Reovirus, and this showed that this tumor type could be targeted by the virus. Indeed, infected MPM cells showed strong viral protein production, and a decrease of the size of an invaded lymph node was also observed in this patient after six cycles of docetaxel/reovirus combination. $^{48}$

Finally, retroviral replicating vectors have been shown to efficiently transduce human MM cells both in vitro and in vivo in subcutaneous xenograft models. ${ }^{49,50}$ The vectors that were used in this study encode a prodrug activator gene that sensitizes tumor cells to the prodrug, 5-fluorocytosine. Tumor cells and their healthy counterparts were reported to exhibit different expression levels of the retrovirus receptors, which could account for the oncolytic potential of retroviruses against MM. 


\section{Antitumor immune responses}

Specific lysis of tumor cells is a fundamental feature of oncolytic viruses. Nevertheless, these viruses can exert their antitumor activity through additional mechanisms such as the targeting of tumor vessels ${ }^{51,52}$ or the activation of immune cells. This ability to induce tumor-specific immune responses is now believed to be essential for the antitumor effects that have been observed in patients. ${ }^{53}$ Most of the viruses that are currently being tested in advanced clinical trials are thus designed to activate immune responses that can help their antitumor properties. For instance, Pexa-Vec and T-Vec viruses are engineered to express the human granulocytemacrophage colony-stimulating factor that is necessary for the antitumor effects that have been reported in clinical trials. ${ }^{8} 15$ Likewise, an oncolytic adenovirus coding for human granulocyte-macrophage colony-stimulating factor showed immune activation abilities in a Phase I trial on different types of solid tumors, even though only one of the two patients with MPM included showed disease stabilization, while the other patient exhibited progressive disease..$^{54}$

Back in 2005, Sterman et al hypothesized that the antitumor effects they observed in patients with MPM after intrapleural injection of an oncolytic adenovirus were due to the induction of an antitumor immune response characterized by the production of tumor-specific antibodies. ${ }^{55}$ This was then confirmed with adenoviral vectors encoding the type I interferon genes that were able to activate cytotoxic $\mathrm{T}$ cells, natural killer cells, and humoral responses in the pleural cavity. ${ }^{34,35}$ As discussed earlier, activation of the type I interferon response by oncolytic viruses is a double-edged sword; these interferons have a strong antiviral activity, mainly due to their ability to shut down protein synthesis and to activate cell death programs in infected and neighboring cells. However, they are also strong inducers of the innate immune response that can subsequently initiate specific antitumor responses, and thus synergize with the direct cytotoxic effects of the viruses. ${ }^{56}$

VSV is one of the major oncolytic viruses for which the antitumor immune response is believed to have a central role. Actual oncolytic activity (ie, viral replication in tumor cells) of VSV is not always observed after systemic treatment of animals in vivo, but this virus is extremely efficient in activating specific adaptive immune responses when reaching immune cells in the lymphoid organs. It has been shown that VSV-mIFN $\beta$ encoding the murine interferon- $\beta$ gene is able to induce general CD8 T-cell activation against MPM cells after locoregional delivery of the virus. ${ }^{38}$ Such a mechanism could be exploited to improve the antitumor efficacy of VSV against MM. However, VSV-induced immune responses will need further characterization as the same research group subsequently showed that the virus can also induce a transforming growth factor- $\beta$-dependent suppressive activity mediated by myeloid-derived suppressor cells in a different tumor model. ${ }^{57}$

A critical feature for oncolytic viruses lies in their ability to kill tumor cells by inducing cell death exhibiting immunogenic properties. Different types of immunogenic cell death have been identified, including programmed necrosis - also known as necroptosis - pyroptosis or a specific type of immunogenic apoptosis, most of which are induced by anticancer treatments. ${ }^{58}$ Oncolytic viruses are powerful inducers of tumor cell death and can definitely provide signals bearing immunogenic properties. ${ }^{53,59}$ As an example, we previously showed that MV was able to induce immunogenic cell death in infected human MPM cells. This allows for the activation of central immune cells such as myeloid ${ }^{40}$ and plasmacytoid ${ }^{60}$ dendritic cells that are then able to cross-prime tumor-specific cytotoxic T-cell responses. ${ }^{61}$ There has been a recent interest in stimulating plasmacytoid dendritic cells for the treatment of cancer ${ }^{62}$ that could be largely exploited by developing oncolytic virotherapy for cancers such as MM.

A recent Phase I trial described systemic antitumor effects after MV treatment of two patients with multiple myeloma, which strongly suggests the involvement of the immune system. ${ }^{63}$ This same group previously reported that MV encoding the interferon- $\beta$ gene induced immune cell infiltration - mainly macrophages - into human MM xenografts and the associated microenvironment. ${ }^{41}$ Another study showed that MV is an appropriate vector for immunotherapy when used in combination with anti-PD-L1 or anti-CTLA-4 antibodies. ${ }^{64}$ One recent study also reported the induction of different antitumor immune mechanisms after intratumoral injection of an oncolytic adenovirus (Ad5/3-D24-GMCSF or ONCOS-102) in one patient (Table 1). ${ }^{65}$ These findings require further research to determine how they can be applied to the treatment of MM in patients, but they confirm that viral vectors and oncolytic viruses can be used in antitumor vaccine strategies. One can thus anticipate the use of oncolytic vectors coding for tumor antigens to mount specific immune responses against MM tumors, a strategy that has already been developed for other malignancies. ${ }^{66}$

\section{Treatment combinations}

To date, cancer virotherapy has shown extremely promising results both in preclinical studies and in clinical trials. However, further combinations of oncolytic viruses with other types of cancer treatments could again improve its efficacy. 
In addition, combination studies are of great value because virotherapy is usually tested as a second-line or third-line therapy and it would be interesting to determine how other anticancer therapies could impact - positively or negatively on its efficacy in patients.

Combined treatment with cisplatin plus pemetrexed also known as Alimta - has become the standard of care for MM even though its mild clinical efficacy only accounts for an increased survival of approximately 3 months. ${ }^{7}$ Different studies have been performed to determine whether these chemotherapies can synergize with oncolytic viruses to improve the efficacy of both approaches. It was first shown that the stress response induced by cisplatin in cell lines derived from epithelioid, sarcomatoid, or biphasic MM could potentiate the replication and cytotoxicity of the oncolytic HSVs NV1066 in vitro. ${ }^{10}$ The same group reported that the DNA damage response induced by radiation could also synergize with NV1066 for increased antitumor activity. ${ }^{11}$ It was also shown that the use of a replication-competent adenovirus deficient for E1B-55kDa, or encoding p53, sensitized MM cells to apoptosis and cytotoxicity induced by cisplatin or pemetrexed. ${ }^{30,31}$ These results are extremely interesting because they show that oncolytic viruses could benefit from the chemotherapeutics already used in patients with MM to achieve their antitumor effects.

The antitumor effects of epigenetic drugs have been widely demonstrated for the treatment of hematological cancers, but more work is needed to define their use for solid tumors. Nonetheless, this class of drugs has shown promising results for the treatment of $\mathrm{MM}^{67,68}$ and also exhibits different types of actions that could enhance or interfere with oncolytic virus activities. Indeed, inhibitors of histone deacetylases have been demonstrated to synergize with certain oncolytic viruses such as VSV to infect refractory primary tumors by dampening the type I interferon response. ${ }^{69}$ Valproic acid was also shown to enhance HSV replication in tumor cells by a similar mechanism. ${ }^{70}$ Analogous studies were carried out with different types of oncolytic viruses and showed a variety of mechanisms, such as anti-angiogenic actions, proapoptotic effects, and upregulation of viral receptors, leading to antitumor activity. ${ }^{71,72}$ Such an approach should thus be considered when designing combinatorial therapeutic strategies using oncolytic viruses for the treatment of MM.

\section{Conclusion}

$\mathrm{MM}$ is an aggressive cancer for which there is an urgent need for the development of efficient, innovative therapeutic strategies to improve its clinical management. Cancer virotherapy is currently one of the most promising alternatives, with several studies having already shown that human MM cells are sensitive to many different oncolytic viruses by direct killing or by immune-mediated mechanisms. Nonetheless, extensive research is necessary to better define the modalities of treatment and to anticipate how experimental data can be applied to the clinical situation in patients. There is a critical need for exclusive MM trials in order to clinically address the specificities of this cancer, which is often included in studies for patients with "solid tumor", with a limited number of actual patients with MM evaluated. Because MM is a relatively rare cancer, it may be difficult to incorporate a large number of patients in a single study, but this effort would ensure the clinical validation of oncolytic virotherapy for this specific malignancy and would hopefully provide a brighter prospect for patients afflicted with this incurable disease.

\section{Acknowledgments}

This work has been supported by "La Ligue Nationale Contre le cancer", "La Ligue Régionale Grand-Ouest Contre le Cancer (CSIRGO)", the "ARSMESO44 association", the "Fondation pour la Recherche Médicale (FRM)" and "La Fondation ARC pour la Recherche sur le Cancer".

\section{Disclosure}

FT, MG, and JFF own patents on the use of attenuated MV for antitumor virotherapy. Other authors report no conflicts of interest in this work.

\section{References}

1. Russell SJ, Peng KW, Bell JC. Oncolytic virotherapy. Nat Biotechnol. 2012;30(7):658-670.

2. Galanis E, Atherton PJ, Maurer MJ, et al. Oncolytic measles virus expressing the sodium iodide symporter to treat drug-resistant ovarian cancer. Cancer Res. 2015;75(1):22-30.

3. Galanis E, Hartmann LC, Cliby WA, et al. Phase I trial of intraperitoneal administration of an oncolytic measles virus strain engineered to express carcinoembryonic antigen for recurrent ovarian cancer. Cancer Res. 2010;70(3):875-882.

4. Porpodis K, Zarogoulidis P, Boutsikou E, et al. Malignant pleural mesothelioma: current and future perspectives. J Thorac Dis. 2013; 5(Suppl 4):S397-S406.

5. Roe OD, Stella GM. Malignant pleural mesothelioma: history, controversy and future of a manmade epidemic. Eur Respir Rev. 2015; 24(135):115-131.

6. Husain AN, Colby T, Ordonez N, et al; International Mesothelioma Interest Group. Guidelines for pathologic diagnosis of malignant mesothelioma: 2012 update of the consensus statement from the International Mesothelioma Interest Group. Arch Pathol Lab Med. 2013;137(5): 647-667.

7. Scherpereel A, Astoul P, Baas P, et al. Guidelines of the European Respiratory Society and the European Society of Thoracic Surgeons for the management of malignant pleural mesothelioma. Eur Respir J. 2010;35(3):479-495. 
8. Senzer NN, Kaufman HL, Amatruda T, et al. Phase II clinical trial of a granulocyte-macrophage colony-stimulating factor-encoding, secondgeneration oncolytic herpesvirus in patients with unresectable metastatic melanoma. J Clin Oncol. 2009;27(34):5763-5771.

9. Kucharczuk JC, Randazzo B, Chang MY, et al. Use of a "replicationrestricted" herpes virus to treat experimental human malignant mesothelioma. Cancer Res. 1997;57(3):466-471.

10. Adusumilli PS, Chan MK, Chun YS, et al. Cisplatin-induced GADD34 upregulation potentiates oncolytic viral therapy in the treatment of malignant pleural mesothelioma. Cancer Biol Ther. 2006; $5(1): 48-53$.

11. Adusumilli PS, Chan MK, Hezel M, et al. Radiation-induced cellular DNA damage repair response enhances viral gene therapy efficacy in the treatment of malignant pleural mesothelioma. Ann Surg Oncol. 2007;14(1):258-269.

12. Adusumilli PS, Eisenberg DP, Stiles BM, et al. Intraoperative localization of lymph node metastases with a replication-competent herpes simplex virus. J Thorac Cardiovasc Surg. 2006;132(5):1179-1188.

13. Adusumilli PS, Stiles BM, Chan MK, et al. Imaging and therapy of malignant pleural mesothelioma using replication-competent herpes simplex viruses. J Gene Med. 2006;8(5):603-615.

14. Adusumilli PS, Eisenberg DP, Chun YS, et al. Virally directed fluorescent imaging improves diagnostic sensitivity in the detection of minimal residual disease after potentially curative cytoreductive surgery. J Gastrointest Surg. 2005;9(8):1138-1146. [discussion 1146-1137].

15. Heo J, Reid T, Ruo L, et al. Randomized dose-finding clinical trial of oncolytic immunotherapeutic vaccinia JX-594 in liver cancer. Nat Med. 2013;19(3):329-336.

16. Breitbach CJ, Burke J, Jonker D, et al. Intravenous delivery of a multimechanistic cancer-targeted oncolytic poxvirus in humans. Nature. 2011;477(7362):99-102.

17. Belin LJ, Ady JW, Lewis C, et al. An oncolytic vaccinia virus expressing the human sodium iodine symporter prolongs survival and facilitates SPECT/CT imaging in an orthotopic model of malignant pleural mesothelioma. Surgery. 2013;154(3):486-495.

18. Brader P, Kelly KJ, Chen N, et al. Imaging a genetically engineered oncolytic vaccinia virus (GLV-1h99) using a human norepinephrine transporter reporter gene. Clin Cancer Res. 2009;15(11):3791-3801.

19. Kelly KJ, Woo Y, Brader P, et al. Novel oncolytic agent GLV-1h68 is effective against malignant pleural mesothelioma. Hum Gene Ther. 2008;19(8):774-782.

20. Acuna SA, Ottolino-Perry K, Cako B, Tang N, Angarita FA, McCart JA. Oncolytic vaccinia virus as an adjuvant treatment to cytoreductive surgery for malignant peritoneal mesothelioma. Ann Surg Oncol. 2014;21(7):2259-2266.

21. Mukherjee S, Haenel T, Himbeck R, et al. Replication-restricted vaccinia as a cytokine gene therapy vector in cancer: persistent transgene expression despite antibody generation. Cancer Gene Ther. 2000; 7(5):663-670.

22. Garber K. China approves world's first oncolytic virus therapy for cancer treatment. J Natl Cancer Inst. 2006;98(5):298-300.

23. Zhu ZB, Makhija SK, Lu B, et al. Targeting mesothelioma using an infectivity enhanced survivin-conditionally replicative adenoviruses J Thorac Oncol. 2006;1(7):701-711.

24. Fukazawa T, Matsuoka J, Naomoto Y, Maeda Y, Durbin ML, Tanaka N. Malignant pleural mesothelioma-targeted CREBBP/EP300 inhibitory protein 1 promoter system for gene therapy and virotherapy. Cancer Res. 2008;68(17):7120-7129.

25. Watanabe Y, Kojima T, Kagawa S, et al. A novel translational approach for human malignant pleural mesothelioma: heparanase-assisted dual virotherapy. Oncogene. 2010;29(8):1145-1154.

26. Gotoh A, Kanno T, Nagaya H, et al. Gene therapy using adenovirus against malignant mesothelioma. Anticancer Res. 2012;32(9):3743-3747.

27. Kubo S, Kawasaki Y, Yamaoka N, et al. Complete regression of human malignant mesothelioma xenografts following local injection of midkine promoter-driven oncolytic adenovirus. J Gene Med. 2010; 12(8):681-692.
28. Takagi-Kimura M, Yamano T, Tamamoto A, et al. Enhanced antitumor efficacy of fiber-modified, midkine promoter-regulated oncolytic adenovirus in human malignant mesothelioma. Cancer Sci. 2013; 104(11):1433-1439.

29. Tsuruta Y, Pereboeva L, Breidenbach M, et al. A fiber-modified mesothelin promoter-based conditionally replicating adenovirus for treatment of ovarian cancer. Clin Cancer Res. 2008;14(11):3582-3588.

30. Yamanaka M, Tada Y, Kawamura K, et al. E1B-55 kDa-defective adenoviruses activate p53 in mesothelioma and enhance cytotoxicity of anticancer agents. J Thorac Oncol. 2012;7(12):1850-1857.

31. Li Q, Kawamura K, Yamanaka M, et al. Upregulated p53 expression activates apoptotic pathways in wild-type p53-bearing mesothelioma and enhances cytotoxicity of cisplatin and pemetrexed. Cancer Gene Ther. 2012;19(3):218-228.

32. Frizelle SP, Grim J, Zhou J, et al. Re-expression of p16INK4a in mesothelioma cells results in cell cycle arrest, cell death, tumor suppression and tumor regression. Oncogene. 1998;16(24):3087-3095.

33. Yang CT, You L, Yeh CC, et al. Adenovirus-mediated p14(ARF) gene transfer in human mesothelioma cells. J Natl Cancer Inst. 2000;92(8):636-641.

34. Sterman DH, Haas A, Moon E, et al. A trial of intrapleural adenoviralmediated Interferon-alpha2b gene transfer for malignant pleural mesothelioma. Am J Respir Crit Care Med. 2011;184(12):1395-1399.

35. Sterman DH, Recio A, Carroll RG, et al. A phase I clinical trial of single-dose intrapleural IFN-beta gene transfer for malignant pleural mesothelioma and metastatic pleural effusions: high rate of antitumor immune responses. Clin Cancer Res. 2007;13(15 pt 1):4456-4466.

36. Sterman DH, Recio A, Haas AR, et al. A phase I trial of repeated intrapleural adenoviral-mediated interferon-beta gene transfer for mesothelioma and metastatic pleural effusions. Mol Ther. 2010;18(4):852-860.

37. Tagawa M, Tada Y, Shimada H, Hiroshima K. Gene therapy for malignant mesothelioma: current prospects and challenges. Cancer Gene Ther. 2013;20(3):150-156.

38. Willmon CL, Saloura V, Fridlender ZG, et al. Expression of IFN-beta enhances both efficacy and safety of oncolytic vesicular stomatitis virus for therapy of mesothelioma. Cancer Res. 2009;69(19):7713-7720.

39. Saloura V, Wang LC, Fridlender ZG, et al. Evaluation of an attenuated vesicular stomatitis virus vector expressing interferon-beta for use in malignant pleural mesothelioma: heterogeneity in interferon responsiveness defines potential efficacy. Hum Gene Ther. 2010;21(1):51-64.

40. Gauvrit A, Brandler S, Sapede-Peroz C, Boisgerault N, Tangy F, Gregoire M. Measles virus induces oncolysis of mesothelioma cells and allows dendritic cells to cross-prime tumor-specific CD8 response. Cancer Res. 2008;68(12):4882-4892.

41. Li H, Peng KW, Dingli D, Kratzke RA, Russell SJ. Oncolytic measles viruses encoding interferon beta and the thyroidal sodium iodide symporter gene for mesothelioma virotherapy. Cancer Gene Ther. 2010; 17(8):550-558.

42. Phuong LK, Allen C, Peng KW, et al. Use of a vaccine strain of measles virus genetically engineered to produce carcinoembryonic antigen as a novel therapeutic agent against glioblastoma multiforme. Cancer Res. 2003;63(10):2462-2469.

43. Myers RM, Greiner SM, Harvey ME, et al. Preclinical pharmacology and toxicology of intravenous MV-NIS, an oncolytic measles virus administered with or without cyclophosphamide. Clin Pharmacol Ther. 2007;82(6):700-710.

44. Lapp S, Pfankuche VM, Baumgartner W, Puff C. Viral oncolysis - can insights from measles be transferred to canine distemper virus? Viruses. 2014;6(6):2340-2375.

45. Morodomi Y, Yano T, Kinoh H, et al. BioKnife, a uPA activitydependent oncolytic Sendai virus, eliminates pleural spread of malignant mesothelioma via simultaneous stimulation of uPA expression. Mol Ther. 2012;20(4):769-777.

46. Silberhumer GR, Brader P, Wong J, et al. Genetically engineered oncolytic Newcastle disease virus effectively induces sustained remission of malignant pleural mesothelioma. Mol Cancer Ther. 2010; 9(10):2761-2769. 
47. Galanis E, Markovic SN, Suman VJ, et al. Phase II trial of intravenous administration of Reolysin((R)) (Reovirus Serotype-3-dearing Strain) in patients with metastatic melanoma. Mol Ther. 2012; 20(10):1998-2003.

48. Comins C, Spicer J, Protheroe A, et al. REO-10: a phase I study of intravenous reovirus and docetaxel in patients with advanced cancer. Clin Cancer Res. 2010;16(22):5564-5572.

49. KawasakiY, Tamamoto A, Takagi-Kimura M, et al. Replication-competent retrovirus vector-mediated prodrug activator gene therapy in experimental models of human malignant mesothelioma. Cancer Gene Ther. 2011;18(8):571-578.

50. Kubo S, Takagi-Kimura M, Logg CR, Kasahara N. Highly efficient tumor transduction and antitumor efficacy in experimental human malignant mesothelioma using replicating gibbon ape leukemia virus. Cancer Gene Ther. 2013;20(12):671-677.

51. Breitbach CJ, Arulanandam R, De Silva N, et al. Oncolytic vaccinia virus disrupts tumor-associated vasculature in humans. Cancer Res. 2013;73(4):1265-1275.

52. Breitbach CJ, De Silva NS, Falls TJ, et al. Targeting tumor vasculature with an oncolytic virus. Mol Ther. 2011;19(5):886-894.

53. Elsedawy NB, Russell SJ. Oncolytic vaccines. Expert Rev Vaccines. 2013;12(10):1155-1172.

54. Cerullo V, Pesonen S, Diaconu I, et al. Oncolytic adenovirus coding for granulocyte macrophage colony-stimulating factor induces antitumoral immunity in cancer patients. Cancer Res. 2010;70(11):4297-4309.

55. Sterman DH, Recio A, Vachani A, et al. Long-term follow-up of patients with malignant pleural mesothelioma receiving high-dose adenovirus herpes simplex thymidine kinase/ganciclovir suicide gene therapy. Clin Cancer Res. 2005;11(20):7444-7453.

56. Gajewski TF, Corrales L. New perspectives on type I IFNs in cancer. Cytokine Growth Factor Rev. 2015;26(2):175-178.

57. Willmon C, Diaz RM, Wongthida P, et al. Vesicular stomatitis virus-induced immune suppressor cells generate antagonism between intratumoral oncolytic virus and cyclophosphamide. Mol Ther. 2011; 19(1):140-149.

58. Inoue H, Tani K. Multimodal immunogenic cancer cell death as a consequence of anticancer cytotoxic treatments. Cell Death Differ. 2014;21(1):39-49.

59. Achard C, Boisgerault N, Delaunay T, Tangy F, Gregoire M, Fonteneau JF. Induction of immunogenic tumor cell death by attenuated oncolytic measles virus. J Clin Cell Immunol. 2015;6(1):291.
60. Guillerme JB, Boisgerault N, Roulois D, et al. Measles virus vaccineinfected tumor cells induce tumor antigen cross-presentation by human plasmacytoid dendritic cells. Clin Cancer Res. 2013;19(5):1147-1158.

61. Fonteneau JF, Guillerme JB, Tangy F, Gregoire M. Attenuated measles virus used as an oncolytic virus activates myeloid and plasmacytoid dendritic cells. Oncoimmunology. 2013;2(5):e24212.

62. Tel J, de Vries IJ. Potential applications for plasmacytoid dendritic cells in cancer immunotherapy. Immunotherapy. 2012;4(10):979-982.

63. Russell SJ, Federspiel MJ, Peng KW, et al. Remission of disseminated cancer after systemic oncolytic virotherapy. Mayo Clinic Proceed. 2014; 89(7):926-933

64. Engeland CE, Grossardt C, Veinalde R, et al. CTLA-4 and PD-L1 checkpoint blockade enhances oncolytic measles virus therapy. Mol Ther. 2014;22(11):1949-1959.

65. Ranki T, Joensuu T, Jäger E, et al. Local treatment of a pleural mesothelioma tumor with ONCOS-102 induces a systemic antitumor CD8 T-cell response, prominent infiltration of CD8 lymphocytes and Th1 type polarization. Oncoimmunology. 2014;3(10):e958937.

66. Rajani K, Alonso-Camino V, Boisgerault N, Vile R. Viral platforms for expression of tumor antigens in cancer immunotherapy. In: Rees RC, editor. Tumor Immunology and Immunotherapy. Oxford: Oxford University Press; 2014:217-234.

67. Guillot F, Boutin B, Blanquart C, et al. Vaccination with epigenetically treated mesothelioma cells induces immunisation and blocks tumour growth. Vaccine. 2011;29(33):5534-5543.

68. Leclercq S, Gueugnon F, Boutin B, et al. A 5-aza-2'-deoxycytidine/ valproate combination induces cytotoxic T-cell response against mesothelioma. Eur Respir J. 2011;38(5):1105-1116.

69. Nguyên TL, Abdelbary H, Arguello M, et al. Chemical targeting of the innate antiviral response by histone deacetylase inhibitors renders refractory cancers sensitive to viral oncolysis. Proc Natl Acad Sci USA. 2008;105(39):14981-14986.

70. Otsuki A, Patel A, Kasai K, et al. Histone deacetylase inhibitors augment antitumor efficacy of herpes-based oncolytic viruses. Mol Ther. 2008;16(9):1546-1555.

71. Nguyen TL, Wilson MG, Hiscott J. Oncolytic viruses and histone deacetylase inhibitors - a multi-pronged strategy to target tumor cells. Cytokine Growth Factor Rev. 2010;21(2-3):153-159.

72. Forbes NE, Abdelbary H, Lupien M, Bell JC, Diallo JS. Exploiting tumor epigenetics to improve oncolytic virotherapy. Front Genet. 2013;4:184
Oncolytic Virotherapy

\section{Publish your work in this journal}

Oncolytic Virotherapy is an international, peer-reviewed, open access online journal publishing original research, study protocols, reviews, editorials and commentaries on all aspects of oncolytic virology, namely the application of oncolytic viruses for the treatment of cancer. Specific topics in the journal include: Rationale and theoretical aspects of oncolytic virotherapy including in vitro, in vivo and mathematical

Submit your manuscript here: http://www.dovepress.com/oncolytic-virotherapy-journal

\section{Dovepress}

modeling; and practical application and problem solving in the clinic including identification of potential responders through biomarkers and genetic profiling. The manuscript management system is completely online and includes a very quick and fair peer-review system, which is all easy to use. Visit http://www.dovepress.com/ testimonials.php to read real quotes from published authors. 